\title{
Influence of Dissolution on Fate of Nanoparticles in Freshwater
}

\author{
Yubing Pu, Bertrand Laratte, and Rodica Elena Ionescu
}

\begin{abstract}
The fate of engineering nanoparticles (ENPs) determines how long they stay in a certain compartment such as freshwater. Many factors such as diameter of suspended particles in freshwater, depth of freshwater, may affect the fate of ENPs in freshwater with different extent. Dissolution rate $\left(k_{\text {diss }}\right)$ of ENPs has been demonstrated as one of the most significant parameters. However, the influences of $k_{\text {diss }}$ on relative importance of the other parameters are still not clear. In this study, the relative importance of four parameters has been calculated with the $\boldsymbol{k}_{\text {diss }}$ being fixed to eight different values respectively. The relative importance decreases along with the increasing $k_{\text {diss }}$ values. The results are well fitted $\left(R^{2}>0.999\right)$ by an exponential associate function, which simplifies the calculation of the relative importance of the studied parameters.
\end{abstract}

Index Terms-Dissolution rate, fate model, nanoparticle, sensitivity analysis, exponential associate function.

\section{INTRODUCTION}

The production and application of engineering nanoparticles (ENPs) are increasing rapidly due to their relatively specific characteristics compared to their bulk counterparts. Ref. [1]-[3] the wastewater treatment plant (WWTP) effluent is the main source of the ENPs in aquatic ecosystems. Ref. [4] fate describes the possible transport and destination of a substance. After the ENPs release into freshwater, many behaviors may occur (such as dissolution, aggregation, and transformation [5]) which are usually addressed as the fate of ENPs. Essentially, dissolution of ENPs is a transformation process from their solid form to the dissolved ionic form or other intermediates. Ref. [6] there are two important elements related to dissolution: solubility and dissolution rate. Solubility is the maximum amount of a solute (in this study is the ENPs) that a solvent can hold in solution at certain conditions. Dissolution rate presents how long it takes to get the saturation concentration of a solute.

Manuscript received September 22, 2016; revised December 22, 2016.

Yubing $\mathrm{Pu}$ is with the Laboratoire de Nanotechnologie et d'Instrumentation Optique and the Centre de Recherches et d'Etudes Interdisciplinaires sur le Développement Durable, ICD, UMR-CNRS 6281, Université de Technologie de Troyes, 10004 Troyes cedex, France (e-mail: yubing.pu@utt.fr).

Bertrand Laratte was with the Centre de Recherches et d'Etudes Interdisciplinaires sur le Développement Durable, Université de Technologie de Troyes, 10004 Troyes, France. He is now with the Institute of Mechanics and Engineering, I2M, UMR-CNRS 5295, Arts et Métiers ParisTech, 33405 Talence cedex, France and Technopole Izarbel, APESA, 64210 Bidart, France (e-mail: bertrand.laratte@utt.fr, bertrand.laratte@ensam.eu).

Rodica Elena Ionescu is with the Laboratoire de Nanotechnologie et d'Instrumentation Optique, Université de Technologie de Troyes, ICD, UMR-CNRS 6281, 10004 Troyes cedex, France (e-mail: elena_rodica.ionescu@utt.fr).
Solubility is an endpoint, while dissolution rate is a kinetic process. Although the solubility and dissolution rate are different concepts, they are related. Based on the famous Noyes-Whitney equation, when dissolution is limited by diffusion, dissolution rate has positive correlation with solubility [7].

The dissolution of various ENPs could differ from each other vastly due to their different physical-chemical properties. However, even the same ENPs may have very different solubility and dissolution rate because of the different environmental conditions. For example, titanium dioxide nanoparticles (nano- $\mathrm{TiO}_{2}$ ) were assumed to be practically insoluble in freshwater in many studies, [8], [9] while they were confirmed being able to dissolve in acid aqueous $\mathrm{NaCl}$ solutions $(\mathrm{pH}<3)$ at temperatures of 25 and $37{ }^{\circ} \mathrm{C}$. [10] Dissolution of zinc oxide nanoparticles (nano-ZnO) was observed with 7.18-7.40 mg/L dissolved $\mathrm{Zn}$ in pure water, but with much higher dissolved $\mathrm{Zn}$ concentration (> $34 \mathrm{mg} / \mathrm{L})$ in a cell culture medium [11].

In order to appropriately assess the potential environmental impact of ENPs, many fate models have been developed to predict the fate of ENPs in various environmental media, particularly the aquatic media. Ref. [8], [12] a recently published research has demonstrated that there are many factors affecting the output of fate model, such as dissolution rate of ENPs, diameter of suspended particles in freshwater, depth of freshwater. Among them, dissolution rate is one of the most significant factor for many subcontinental regions [12].

However, directly modeling the dissolution of ENPs to understand its influence on fate of ENPs is difficult. Many factors may affect dissolution of ENPs in freshwater, such as temperature, $\mathrm{pH}$, ion strength, natural organic matters. Ref. [5], [13] Even though some studies have described the dissolution kinetics of ENPs under extreme oxidative, acidic, or alkaline conditions, [14] the modeling of dissolution rate of ENPs in freshwater is complex and still in its infancy. Ref. [11], [12] therefore, in practice, as an acceptable simplification, the dissolution rate constant of ENPs in freshwater is assumed to be $0-10^{-5} \mathrm{~s}^{-1}$ for different ENPs. [14]

In this study, four important input parameters of a fate model were selected. The influences of $k_{\text {diss }}$ on fate model were indirectly investigated by studying the influences of $k_{\text {diss }}$ on the relative importance of the four selected parameters.

\section{METHODS}

\section{A. Fate Model for Enps in Freshwater}

Recently, a fate model based on colloid science has been 
proposed by our group to calculate the persistence time of ENPs in freshwater ecosystem. Ref. [12] its functionality was proved and it could be used to calculate ENPs' characterization factor $(\mathrm{CF})$, an important input parameter in life cycle impact assessment (LCIA).

In the fate model, three behaviors have been considered as removal processes for freshwater after the ENPs released into freshwater: dissolution, sedimentation, and advection to other water compartments. In addition, the fate model considered 17 different subcontinental regions shown in Table I and gave the recommended values for each input parameter. Essentially, the fate model is a mathematical function with many input values. Thus, in this study, the fate model is defined as: $F F\left(\delta_{1}, \delta_{2}, \delta_{3}, \cdots\right)$. The $\delta_{\mathrm{i}}(\mathrm{i}=1,2$, $3, \cdots$ ) represents input parameters (such as radius of ENPs, depth of freshwater). More detailed information about the fate model could be found in the study of $\mathrm{Pu}$, et al. [12].

TABLE I: THE 17 DIFFERENT SUBCONTINENTAL REGIONS CONSIDERED IN THE STUDY OF PU ET AL. [12]

\begin{tabular}{ll}
\hline \hline Region ID & Region* \\
\hline DEFAULT & Unknown region \\
W1 & Central and west Asia \\
W2 & Indochina \\
W3 & Northern Australia \\
W4 & Southern Australia \& New Zealand \\
W5 & Southern Africa \\
W6 & North, West, East \& Central Africa \\
W7 & Argentina+ \\
W8 & Brazil+ \\
W9 & Central America+ \& Caribbean \\
W10 & USA \& Southern Canada \\
W12 & Northern Europe \& Northern Canada \\
W13 & Europe \\
W14 & East Indies \& Pacific \\
CHI & Eastern China \\
JAP & Japan \& Korean peninsula \\
IND & India+ \\
\hline \hline
\end{tabular}

*The further details about the countries within each region can be found in the study of Shaked. [15]

\section{B. Sensitivity Analysis of Fate Model}

Since the input values of fate model may vary in different literature sources, a sensitivity analysis for studying the influences of main input parameters on output results was carried out in previous study.[12] By doing this, it was possible to determine which input parameter should receive more attention in the future. One of the methods used in the study was labeled as "Single Parameter SA".[12] It was performed by varying each selected parameter within its range while holding the others constant. There were 13 parameters involved in total. The recommended values and ranges of main input parameters are listed in Table II. The first five parameters with high relative importance follow the order shown in (1), while the relative importance of the other studied parameters was at least 3 orders of magnitude lower compared to the first fives.[12]

$$
k_{\text {diss }}>r_{\mathrm{LSP}}>\rho_{\mathrm{SNP}}>\alpha_{2} \approx \text { Depth }_{\text {water }}
$$

where $k_{\text {diss }}$ is the dissolution rate of ENPs in freshwater; $r_{\mathrm{LSP}}$ is the radius of larger suspended particles (LSP, > $450 \mathrm{~nm}$ ) in freshwater; $\rho_{\mathrm{SNP}}$ is the density of the suspended particles in freshwater; $\alpha_{2}$ is the attachment efficiency between ENPs and LSP; Depth $h_{\text {water }}$ is the depth of freshwater.

TABLE II: RECOMMENDED VALUES AND RANGES OF FIVE INPUT PARAMETERS FOR THE SENSITIVITY ANALYSIS EXTRACTED FROM THE STUDY OF PU ET AL. [12]

\begin{tabular}{lllll}
\hline \hline Parameter & Unit & Value & Range & Reference \\
\hline$k_{\text {diss }}$ & $\mathrm{s}^{-1}$ & $5 \cdot 10^{-6}$ & $0-1 \cdot 10^{-5}$ & {$[12],[14]$} \\
$r_{\text {LSP }}$ & & & & {$[12],[16]$,} \\
$\rho_{\mathrm{SNP}}$ & $\mathrm{m}$ & $1.05 \cdot 10^{-5}$ & $5 \cdot 10^{-7}-1 \cdot 10^{-4}$ & {$[17]$} \\
$\alpha_{2}$ & -- & 0.9 & $0.001-1$ & {$[12],[16]$} \\
Depth $_{\text {water }}$ & $\mathrm{m}$ & -- & $0.5-2$ Depth $_{\text {water }}$ & {$[12],[18]$} \\
\hline \hline
\end{tabular}

\section{Sensitivity Analysis with Different Dissolution Rate}

In the sensitivity analysis of fate model in the study of $\mathrm{Pu}$ et al. [12], the $k_{\mathrm{diss}}$ of ENPs was set as $5 \cdot 10^{-6} \mathrm{~s}^{-1}$ as shown in Table II by the method "Single Parameter SA" when assessing the other parameters' relative importance. However, because the $k_{\text {diss }}$ of ENPs is the most important parameter for many studied regions [12] and could be any value between 0 and $1 \cdot 10^{-5} \mathrm{~s}^{-1}$, [14] the different $k_{\text {diss }}$ values may have big influences on the sensitivity analysis results. Thus, in this study, eight values of $k_{\text {diss }}$ have been selected to explore their potential influence on sensitivity analysis results. The eight selected values of $k_{\text {diss }}$ are $0,1 \cdot 10^{-7} \mathrm{~s}^{-1}, 5 \cdot 10^{-7} \mathrm{~s}^{-1}, 1 \cdot 10^{-6} \mathrm{~s}^{-1}$, $3 \cdot 10^{-6} \mathrm{~s}^{-1}, 5 \cdot 10^{-6} \mathrm{~s}^{-1}, 7 \cdot 10^{-6} \mathrm{~s}^{-1}$, and $1 \cdot 10^{-5} \mathrm{~s}^{-1}$, respectively.

In practice, the fate model is simplified as a model with five variables (A), (B), (C), (D), (E)) as shown in Fig. 1. From the aspect of computational mathematics, the fate model can be expressed as:

$$
F F\left(k_{\mathrm{diss}}, r_{\mathrm{LSP}}, \rho_{\mathrm{SNP}}, \alpha_{2}, \operatorname{Depth}_{\mathrm{water}}\right)
$$

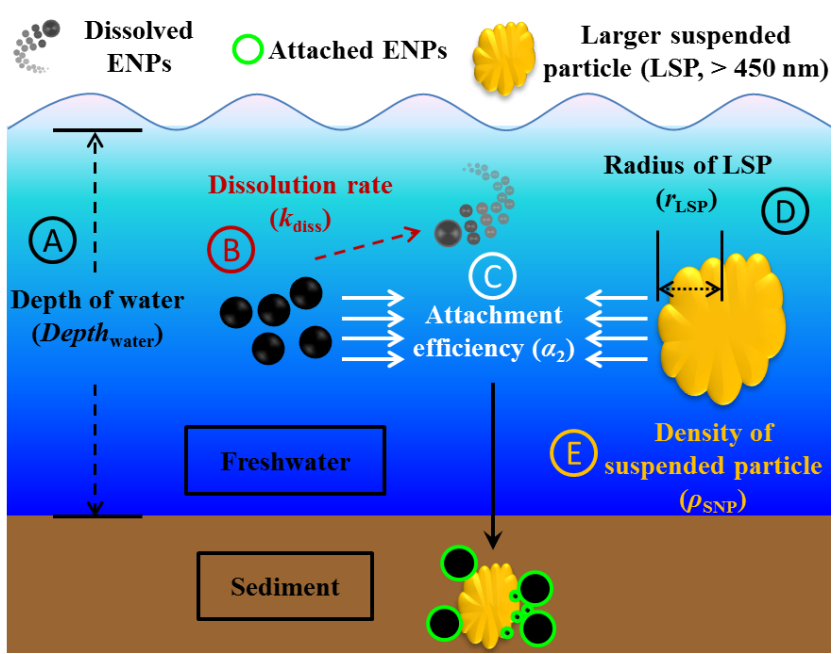

Fig. 1 . The five fate model input parameters considered in this study: $k_{\text {diss, }}$ Depth $_{\text {water }}, \alpha_{2}, r_{\mathrm{LSP}}$, and $\rho_{\mathrm{SNP}}$.

The values and ranges of the four parameters ( $r_{\mathrm{LSP}}, \rho_{\mathrm{SNP}}, \alpha_{2}$, and Depth water $)$ are listed in Table II. All the other parameters are considered as constants and can be found in the study of $\mathrm{Pu}$ et al. [12] The method for doing sensitivity analysis is the same as "Single Parameter SA" by software MATLAB. [12], [19] When one parameter $(\delta)$ changes its value in its range, the other parameters stay as constants. In this way, a 
maximum $\left(F F(\delta)_{\max }\right)$ and minimum $\left(F F(\delta)_{\min }\right)$ value can be obtained. The difference between $F F(\delta)$ max and $F F(\delta)$ min is defined as $\operatorname{DFF}(\delta)$ :

$$
\operatorname{DFF}(\delta)=F F(\delta)_{\max }-F F(\delta)_{\min }
$$

The value of $\operatorname{DFF}(\delta)$ represents the relative importance of the parameter $\delta$ for one given region.

\section{RESULTS AND DISCUSSIONS}

A. Relative Importance of Four Studied Parameters in 17 Subcontinental Regions
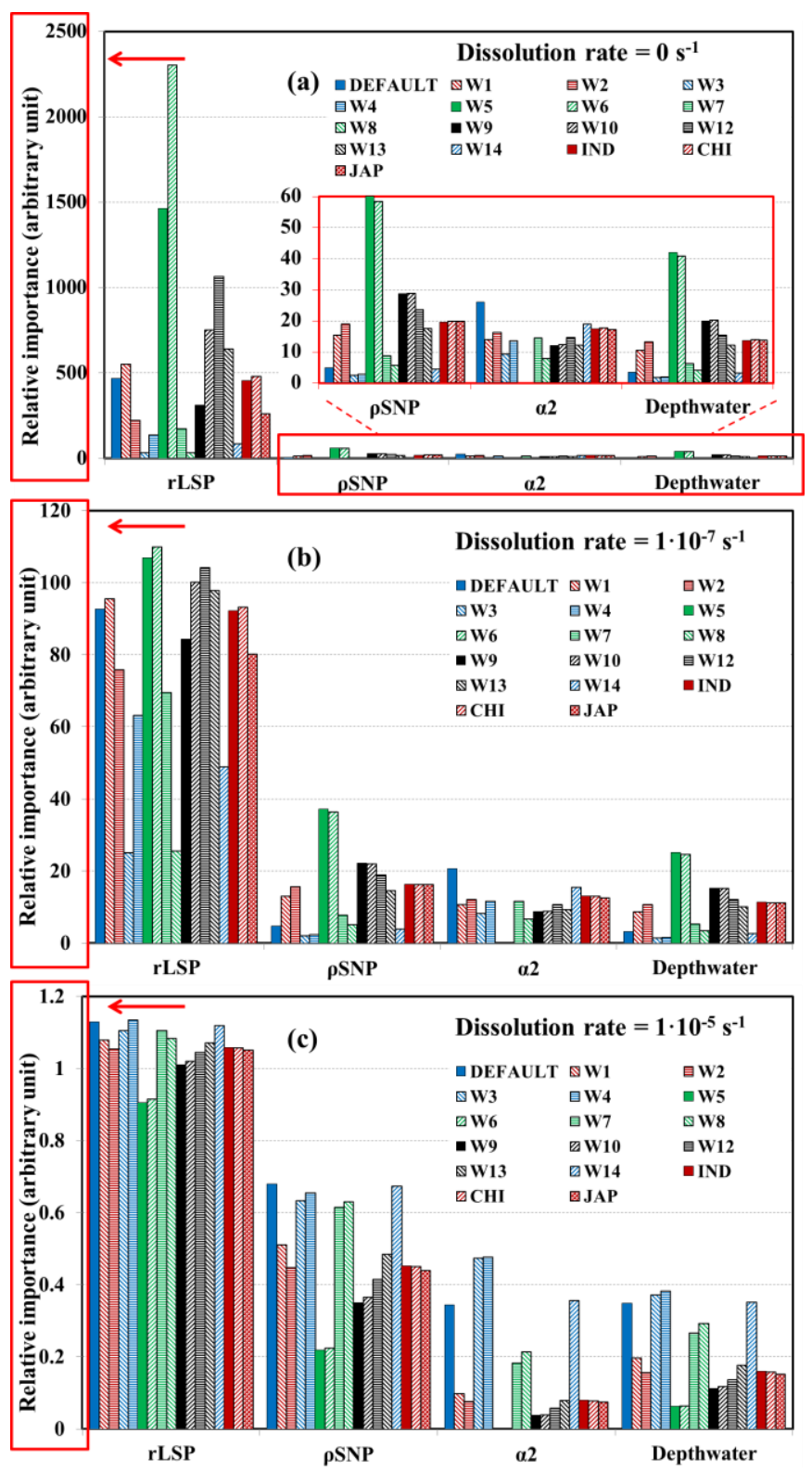

Fig. 2. Relative importance of the four studied parameters $\left(r_{\mathrm{LSP}}, \rho_{\mathrm{SNP}}, \alpha_{2}\right.$, and Dept $_{\text {water }}$ ) in 17 subcontinental regions for ENPs' fate model, when (a) $k_{\text {diss }}=$ 0 ; (b) $k_{\text {diss }}=1 \cdot 10^{-7} \mathrm{~s}^{-1}$; (c) $k_{\text {diss }}=1 \cdot 10^{-5} \mathrm{~s}^{-1}$.

The tables in Appendix list the relative importance of the four studied parameters $\left(r_{\mathrm{LSP}}, \rho_{\mathrm{SNP}}, \alpha_{2}\right.$, and Dept $\left.h_{\text {water }}\right)$ in 17 subcontinental regions for ENPs' fate model, when the $k_{\text {diss }}$ respectively equals 0 (Table III), $1 \cdot 10^{-7} \mathrm{~s}^{-1}$ (Table IV), $5 \cdot 10^{-7}$ $\mathrm{s}^{-1}$ (Table V), $1 \cdot 10^{-6} \mathrm{~s}^{-1}$ (Table VI), $3 \cdot 10^{-6} \mathrm{~s}^{-1}$ (Table VII), $7 \cdot 10^{-6} \mathrm{~s}^{-1}$ (Table VIII), and $1 \cdot 10^{-5}$ (Table IX). The results related to $k_{\text {diss }}=5 \cdot 10^{-6} \mathrm{~s}^{-1}$ were described in the study of Pu et al. [12] Here, three scenarios were shown by Fig. 2. Fig. 2(a) represents the case of insoluble ENPs with $k_{\text {diss }}=0$, while Fig. 2(c) is the situation of the ENPs with very quick dissolution rate equaling $1 \cdot 10^{-5} \mathrm{~s}^{-1}$. Fig. 2(b) shows a general case $\left(k_{\text {diss }}=\right.$ $\left.1 \cdot 10^{-7} \mathrm{~s}^{-1}\right)$ between the two extreme situations.

It is obvious that the relative importance of a certain parameter for the same region under different dissolution rates of ENPs has big differences. The scales of vertical axis for the three scenarios are $10^{3}\left(k_{\text {diss }}=0\right.$, Fig. $\left.2(\mathrm{a})\right), 10^{2}\left(k_{\text {diss }}=\right.$ $1 \cdot 10^{-7} \mathrm{~s}^{-1}$, Fig. 2(b)) and $10^{1}\left(k_{\text {diss }}=1 \cdot 10^{-5} \mathrm{~s}^{-1}\right.$, Fig. 2(c)), respectively. In addition, the relative importance of different parameters differs from each other even under the same dissolution rate of ENPs. For example, the relative importance of $r_{\mathrm{LSP}}$ for W6 region (2300.812) is more than 700 times higher than for $\mathrm{W} 3$ region (32.302).

\section{B. Influence of Dissolution Rate on Relative Importance of Four Studied Parameters}

When dissolution rate was fixed to one value, the relative importance of one studied parameter (such as $r_{\mathrm{LSP}}$ and $\rho_{\mathrm{SNP}}$ ) for all the regions were calculated by summing the relative importance values of the same parameter for all the 17 subcontinental regions. The results are shown in Fig. 3. The relative importance of the four studied parameters follows the order below:

$$
r_{\mathrm{LSP}}>\rho_{\mathrm{SNP}}>\alpha_{2} \approx \text { Depth }_{\text {water }}
$$

This order is the same as the one reported in the study of $\mathrm{Pu}$ et al., which demonstrates that the change of dissolution rate will not change the priority of other parameters. However, it should be noted that the relative importance values of the four studied parameters decrease along with the increasing dissolution rates. The relative importance values have dropped dramatically with the dissolution rate lower than $1 \cdot 10^{-6} \mathrm{~s}^{-1}$, while they decrease gradually with the dissolution rate between $1 \cdot 10^{-6}$ and $1 \cdot 10^{-5} \mathrm{~s}^{-1}$.

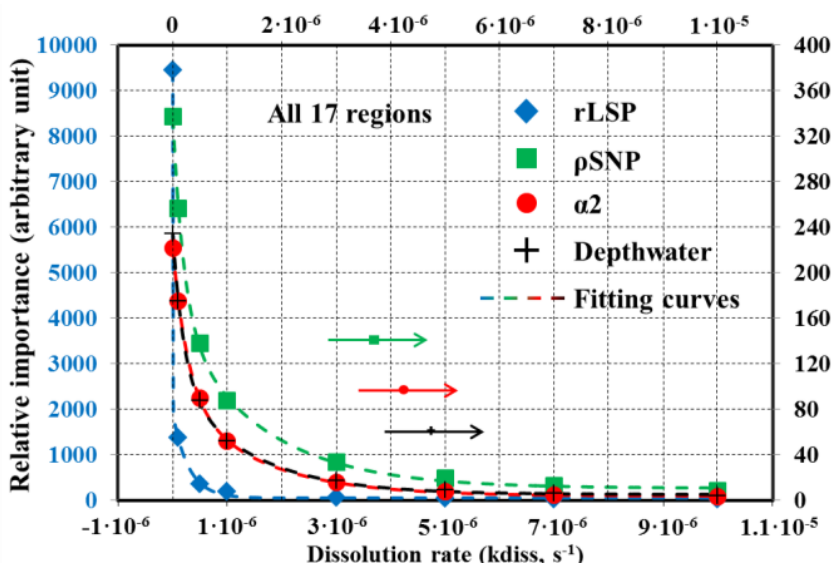

Fig. 3. Influence of dissolution rate on relative importance of the four studied parameters $\left(r_{\mathrm{LSP}}, \rho_{\mathrm{SNP}}, \alpha_{2}\right.$, and Dept $\left._{\text {water }}\right)$ for 17 subcontinental regions.

The four curves in Fig. 3 were fitted by an exponential associate function using Origin 9.0, respectively. All the four coefficients of determination $\left(\mathrm{R}^{2}\right)$ are higher than 0.999 , which indicates that the fitting is quite successful.

The fitting equation is shown in (5) and the values of 
fitting parameters are listed in Table $\mathrm{X}$.

$$
y=A+B \cdot\left(1-e^{(-x / C)}\right)+D \cdot\left(1-e^{(-x / E)}\right)
$$

where $y$ represents the relative importance of one given parameter (i.e. $r_{\mathrm{LSP}}, \rho_{\mathrm{SNP}}, \alpha_{2}$, and Dept $_{\text {water }}$ ) for 17 subcontinental regions and $x$ is the dissolution rate of ENPs. $e$ is the mathematical constant which is approximately equal to 2.71828 .

TABLE X: THE VALUES OF FitTING PARAMETERS AND THE COEFFICIENTS OF DETERMINATION (R2) VALUES FOR THE FOUR STUDIED INPUT PARAMETERS OF FATE MODEL

\begin{tabular}{lllll}
\hline \hline $\begin{array}{l}\text { Fitting } \\
\text { parameters }\end{array}$ & $r_{\mathrm{LSP}}$ & $\rho_{\mathrm{SNP}}$ & $\alpha_{2}$ & Depth $_{\text {water }}$ \\
\hline$A$ & $9.44 \cdot 10^{3}$ & $3.37 \cdot 10^{2}$ & $2.21 \cdot 10^{2}$ & $2.33 \cdot 10^{2}$ \\
$B$ & $-1.85 \cdot 10^{3}$ & $-1.78 \cdot 10^{2}$ & $-1.28 \cdot 10^{2}$ & $-1.29 \cdot 10^{2}$ \\
$C$ & $2.90 \cdot 10^{-7}$ & $2.05 \cdot 10^{-7}$ & $2.75 \cdot 10^{-7}$ & $2.04 \cdot 10^{-7}$ \\
$D$ & $-7.54 \cdot 10^{3}$ & $-1.48 \cdot 10^{2}$ & $-8.95 \cdot 10^{1}$ & $-9.94 \cdot 10^{1}$ \\
$E$ & $6.40 \cdot 10^{-11}$ & $1.59 \cdot 10^{-6}$ & $1.49 \cdot 10^{-6}$ & $1.38 \cdot 10^{-6}$ \\
$\mathrm{R}^{2}$ & 0.99974 & 0.99911 & 0.99971 & 0.99928 \\
\hline \hline
\end{tabular}

Interestingly, the relative importance of one studied parameter (such as $r_{\mathrm{LSP}}, \rho_{\mathrm{SNP}}$ ) for one subcontinental region (W1, W2, JAP, etc.) can also be well fitted by (5). One example of JAP region is shown in Fig. 4. The fitting parameters and coefficients of determination are listed in Table XI. The results for other regions are listed in tables from Table XII to Table XXVII, respectively.

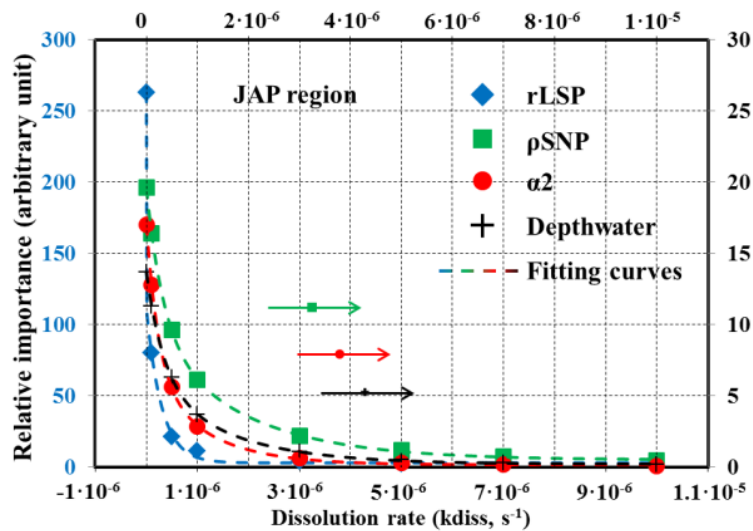

Fig. 4. Influence of dissolution rate on relative importance of the four studied parameters $\left(r_{\mathrm{LSP}}, \rho_{\mathrm{SNP}}, \alpha_{2}\right.$, and $\left.D e p t h_{\text {water }}\right)$ for JAP region.

Equation (5) and the parameters listed in Table X, Table XI-XXVII can be very practical for predicting the relative importance of the four studied parameters $\left(r_{\mathrm{LSP}}, \rho_{\mathrm{SNP}}, \alpha_{2}\right.$, and Dept $_{\text {water }}$ ) in 17 subcontinental regions (in total or in separate) by just introducing the $k_{\text {diss }}$ value as input data. It is noteworthy that although all the fitting parameters were calculated essentially based on the previous fate model and the recommended values in literature, [12] the results reported in this study can be expediently updated with new available data.

\section{CONCLUSION}

Modeling the fate of ENPs in freshwater is a way to estimate the persistence time of ENPs. Various input parameters (e.g. radius and density of ENPs, depth of freshwater) have different influences on the output of ENP's fate model. Dissolution rate $\left(k_{\text {diss }}\right)$ of ENPs plays an important role in estimation of ENPs' fate in freshwater. It also has significant influence on the relative importance of the other input parameters. The relative importance of the four studied parameters $\left(r_{\mathrm{LSP}}, \rho_{\mathrm{SNP}}, \alpha_{2}\right.$, and Depth $\left.h_{\text {water }}\right)$ decreases along with the increasing $k_{\text {diss }}$ values. The results are well fitted $\left(\mathrm{R}^{2}>0.999\right)$ by an exponential associate function which could be used for predicting the relative importance of the four studied parameters in 17 subcontinental regions (in total or in separate).

\section{APPENDIX}

TABLE III: THE RELATIVE IMPORTANCE (RI, ARBITRARY UNITS) OF FOUR DIFFERENT INPUT PARAMETERS IN FATE MODEL FOR 17 SUBCONTIENTAL REGIONS; DISSOLUTION RATE OF ENPS IS EQUAL TO 0

\begin{tabular}{lllll}
\hline \hline Regions & $\mathrm{RI}\left(r_{\mathrm{LSP}}\right)$ & $\mathrm{RI}\left(\rho_{\mathrm{SNP}}\right)$ & $\mathrm{RI}\left(\alpha_{2}\right)$ & $\mathrm{RI}\left(\right.$ Dept $\left._{\text {water }}\right)$ \\
\hline DEFAULT & 467.005 & 4.886 & 26.134 & 3.415 \\
W1 & 552.736 & 15.285 & 13.732 & 10.276 \\
W2 & 221.949 & 18.773 & 16.169 & 13.084 \\
W3 & 32.302 & 2.266 & 9.176 & 1.580 \\
W4 & 139.565 & 2.603 & 13.351 & 1.817 \\
W5 & 1462.919 & 60.067 & 0.000 & 41.941 \\
W6 & 2300.812 & 58.223 & 0.000 & 40.676 \\
W7 & 174.505 & 8.594 & 14.230 & 5.997 \\
W8 & 32.991 & 5.547 & 7.640 & 3.845 \\
W9 & 313.397 & 28.749 & 12.115 & 20.032 \\
W10 & 752.095 & 28.645 & 12.242 & 20.004 \\
W12 & 1064.061 & 23.522 & 14.496 & 15.120 \\
W13 & 640.396 & 17.268 & 11.926 & 12.061 \\
W14 & 85.272 & 4.248 & 18.793 & 2.964 \\
IND & 455.734 & 19.566 & 17.385 & 13.661 \\
CHI & 482.000 & 19.669 & 17.503 & 13.735 \\
JAP & 263.107 & 19.620 & 17.027 & 13.670 \\
\hline \hline
\end{tabular}

TABLE IV: THE RELATIVE IMPORTANCE (RI, ARBITRARY UNITS) OF FOUR DIFFERENT INPUT PARAMETERS IN FATE MODEL FOR 17 SUBCONTIENTAL

REGIONS; DISSOLUTION RATE OF ENPS IS EQUAL TO $1.0 \cdot 10-7 \mathrm{~S}-1$

\begin{tabular}{lllll}
\hline \hline Regions & $\mathrm{RI}\left(r_{\mathrm{LSP}}\right)$ & $\mathrm{RI}\left(\rho_{\mathrm{SNP}}\right)$ & $\mathrm{RI}\left(\alpha_{2}\right)$ & $\mathrm{RI}\left(\right.$ Dept $\left._{\text {water }}\right)$ \\
\hline DEFAULT & 92.729 & 4.661 & 20.577 & 3.254 \\
W1 & 95.623 & 13.260 & 10.944 & 8.915 \\
W2 & 75.978 & 15.779 & 12.278 & 10.897 \\
W3 & 25.249 & 2.216 & 8.348 & 1.544 \\
W4 & 63.260 & 2.537 & 11.734 & 1.770 \\
W5 & 106.936 & 37.137 & 0.000 & 25.072 \\
W6 & 109.893 & 36.477 & 0.000 & 24.713 \\
W7 & 69.548 & 7.915 & 11.860 & 5.507 \\
W8 & 25.659 & 5.250 & 6.830 & 3.627 \\
W9 & 84.373 & 22.239 & 8.789 & 15.251 \\
W10 & 100.155 & 22.223 & 8.950 & 15.325 \\
W12 & 104.265 & 19.031 & 10.836 & 12.240 \\
W13 & 97.936 & 14.724 & 9.494 & 10.222 \\
W14 & 49.083 & 4.076 & 15.651 & 2.840 \\
IND & 92.199 & 16.353 & 13.067 & 11.328 \\
CHI & 93.229 & 16.426 & 13.139 & 11.380 \\
JAP & 80.282 & 16.377 & 12.785 & 11.305 \\
\hline \hline
\end{tabular}

TABLE V: THE RELATIVE IMPORTANCE (RI, ARBITRARY UNITS) OF FOUR DIFFERENT INPUT PARAMETERS IN FATE MODEL FOR 17 SUBCONTIENTAL REGIONS; DISSOLUTION RATE OF ENPS Is EQUAL TO 5.0 1 10-7 S-1

\begin{tabular}{|c|c|c|c|c|}
\hline Regions & $\mathrm{RI}\left(r_{\mathrm{LSP}}\right)$ & $\operatorname{RI}\left(\rho_{\mathrm{SNP}}\right)$ & $\operatorname{RI}\left(\alpha_{2}\right)$ & $\mathrm{RI}\left(\right.$ Depth $\left._{\text {water }}\right)$ \\
\hline DEFAULT & 22.030 & 3.925 & 10.679 & 2.719 \\
\hline W1 & 22.138 & 8.534 & 5.493 & 5.599 \\
\hline W2 & 20.857 & 9.420 & 5.509 & 6.146 \\
\hline W3 & 13.474 & 2.034 & 6.065 & 1.412 \\
\hline
\end{tabular}




\begin{tabular}{lllll} 
W4 & 19.842 & 2.304 & 7.782 & 1.602 \\
W5 & 22.471 & 13.299 & 0.000 & 7.516 \\
W6 & 22.616 & 13.303 & 0.000 & 7.600 \\
W7 & 20.391 & 5.976 & 6.737 & 4.078 \\
W8 & 13.574 & 4.311 & 4.662 & 2.929 \\
W9 & 21.394 & 11.193 & 3.510 & 6.996 \\
W10 & 22.305 & 11.268 & 3.637 & 7.139 \\
W12 & 22.533 & 10.481 & 4.659 & 6.440 \\
W13 & 22.250 & 9.095 & 4.722 & 6.034 \\
W14 & 18.184 & 3.500 & 9.091 & 2.420 \\
IND & 21.925 & 9.648 & 5.747 & 6.327 \\
CHI & 21.983 & 9.674 & 5.762 & 6.344 \\
JAP & 21.168 & 9.627 & 5.601 & 6.269 \\
\hline \hline
\end{tabular}

\begin{tabular}{lllll} 
W3 & 1.560 & 0.828 & 0.762 & 0.514 \\
W4 & 1.621 & 0.869 & 0.782 & 0.537 \\
W5 & 1.382 & 0.406 & 0.000 & 0.123 \\
W6 & 1.394 & 0.421 & 0.000 & 0.128 \\
W7 & 1.593 & 0.939 & 0.337 & 0.451 \\
W8 & 1.540 & 0.925 & 0.375 & 0.472 \\
W9 & 1.496 & 0.614 & 0.075 & 0.212 \\
W10 & 1.510 & 0.641 & 0.079 & 0.225 \\
W12 & 1.536 & 0.711 & 0.114 & 0.257 \\
W13 & 1.563 & 0.803 & 0.153 & 0.322 \\
W14 & 1.599 & 0.947 & 0.619 & 0.535 \\
IND & 1.549 & 0.759 & 0.152 & 0.293 \\
CHI & 1.549 & 0.758 & 0.152 & 0.292 \\
JAP & 1.541 & 0.743 & 0.146 & 0.283 \\
\hline
\end{tabular}

TABLE VI: THE RELATIVE IMPORTANCE (RI, ARBITRARY UNITS) OF FOUR DIFFERENT INPUT PARAMETERS IN FATE MODEL FOR 17 SUBCONTIENTAL REGIONS; DISSOLUTION RATE OF ENPS IS EQUAL TO 1.0 $10-6 \mathrm{~S}-1$

\begin{tabular}{lllll}
\hline \hline Regions & $\mathrm{RI}\left(r_{\mathrm{LSP}}\right)$ & $\mathrm{RI}\left(\rho_{\mathrm{SNP}}\right)$ & $\mathrm{RI}\left(\alpha_{2}\right)$ & $\mathrm{RI}\left(\right.$ Dept $\left._{\text {water }}\right)$ \\
\hline DEFAULT & 11.269 & 3.265 & 6.318 & 2.230 \\
W1 & 11.257 & 5.767 & 3.008 & 3.606 \\
W2 & 10.896 & 6.063 & 2.814 & 3.664 \\
W3 & 8.509 & 1.844 & 4.437 & 1.272 \\
W4 & 10.674 & 2.064 & 5.345 & 1.426 \\
W5 & 11.170 & 6.596 & 0.000 & 3.177 \\
W6 & 11.218 & 6.659 & 0.000 & 3.252 \\
W7 & 10.808 & 4.528 & 4.058 & 2.993 \\
W8 & 8.536 & 3.502 & 3.193 & 2.322 \\
W9 & 11.001 & 6.536 & 1.659 & 3.664 \\
W10 & 11.248 & 6.619 & 1.737 & 3.779 \\
W12 & 11.328 & 6.445 & 2.308 & 3.666 \\
W13 & 11.278 & 5.987 & 2.558 & 3.717 \\
W14 & 10.168 & 2.965 & 5.707 & 2.024 \\
IND & 11.183 & 6.172 & 2.906 & 3.751 \\
CHI & 11.198 & 6.182 & 2.909 & 3.757 \\
JAP & 10.978 & 6.140 & 2.822 & 3.696 \\
\hline \hline
\end{tabular}

TABLE IX: THE RELATIVE IMPORTANCE (RI, ARBITRARY UNITS) OF FOUR

DIFFERENT INPUT PARAMETERS IN FATE MODEL FOR 17 SUBCONTIENTAL REGIONS; DISSOLUTION RATE OF ENPS IS EQUAL TO 1.0 $10-5 \mathrm{~s}-1$

\begin{tabular}{lllll}
\hline \hline Regions & $\mathrm{RI}\left(r_{\mathrm{LSP}}\right)$ & $\mathrm{RI}\left(\rho_{\mathrm{SNP}}\right)$ & $\mathrm{RI}\left(\alpha_{2}\right)$ & $\mathrm{RI}\left(\right.$ Dept $\left._{\text {water }}\right)$ \\
\hline DEFAULT & 1.130 & 0.679 & 0.344 & 0.348 \\
W1 & 1.080 & 0.513 & 0.099 & 0.198 \\
W2 & 1.054 & 0.448 & 0.078 & 0.158 \\
W3 & 1.105 & 0.634 & 0.475 & 0.374 \\
W4 & 1.134 & 0.656 & 0.478 & 0.383 \\
W5 & 0.905 & 0.218 & 0.000 & 0.063 \\
W6 & 0.915 & 0.227 & 0.000 & 0.065 \\
W7 & 1.105 & 0.615 & 0.185 & 0.268 \\
W8 & 1.084 & 0.631 & 0.215 & 0.295 \\
W9 & 1.010 & 0.350 & 0.038 & 0.112 \\
W10 & 1.021 & 0.367 & 0.041 & 0.119 \\
W12 & 1.045 & 0.417 & 0.059 & 0.138 \\
W13 & 1.071 & 0.486 & 0.081 & 0.178 \\
W14 & 1.119 & 0.674 & 0.358 & 0.352 \\
IND & 1.058 & 0.452 & 0.079 & 0.160 \\
CHI & 1.058 & 0.452 & 0.079 & 0.159 \\
JAP & 1.052 & 0.442 & 0.076 & 0.154 \\
\hline \hline
\end{tabular}

TABLE VII: THE RELATIVE IMPORTANCE (RI, ARBITRARY UNITS) OF FOUR DIFFERENT INPUT PARAMETERS IN FATE MODEL FOR 17 SUBCONTIENTAL REGIONS; DISSOLUTION RATE OF ENPS IS EQUAL TO 3.0 10 -6 S-1

\begin{tabular}{lllll}
\hline \hline Regions & $\mathrm{RI}\left(r_{\mathrm{LSP}}\right)$ & $\mathrm{RI}\left(\rho_{\mathrm{SNP}}\right)$ & $\mathrm{RI}\left(\alpha_{2}\right)$ & $\mathrm{RI}\left(\right.$ Dept $\left._{\text {water }}\right)$ \\
\hline DEFAULT & 3.801 & 1.900 & 1.963 & 1.208 \\
W1 & 3.752 & 2.257 & 0.743 & 1.181 \\
W2 & 3.689 & 2.179 & 0.628 & 1.050 \\
W3 & 3.434 & 1.328 & 1.947 & 0.887 \\
W4 & 3.741 & 1.440 & 2.122 & 0.962 \\
W5 & 3.551 & 1.572 & 0.000 & 0.566 \\
W6 & 3.568 & 1.613 & 0.000 & 0.588 \\
W7 & 3.729 & 2.170 & 1.195 & 1.258 \\
W8 & 3.420 & 1.925 & 1.166 & 1.154 \\
W9 & 3.654 & 2.005 & 0.330 & 0.860 \\
W10 & 3.691 & 2.061 & 0.350 & 0.903 \\
W12 & 3.725 & 2.162 & 0.491 & 0.974 \\
W13 & 3.746 & 2.243 & 0.617 & 1.127 \\
W14 & 3.668 & 1.797 & 1.921 & 1.149 \\
IND & 3.723 & 2.203 & 0.641 & 1.067 \\
CHI & 3.725 & 2.204 & 0.640 & 1.066 \\
JAP & 3.696 & 2.176 & 0.619 & 1.040 \\
\hline \hline
\end{tabular}

TABLE VIII: THE RELATIVE IMPORTANCE (RI, ARBITRARY UNITS) OF FOUR DIFFERENT INPUT PARAMETERS IN FATE MODEL FOR 17 SUBCONTIENTAL REGIONS; DISSOLUTION RATE OF ENPS IS EQUAL TO 7.0 $10-6 \mathrm{~s}-1$

\begin{tabular}{lllll}
\hline \hline Regions & $\mathrm{RI}\left(r_{\mathrm{LSP}}\right)$ & $\mathrm{RI}\left(\rho_{\mathrm{SNP}}\right)$ & $\mathrm{RI}\left(\alpha_{2}\right)$ & $\mathrm{RI}\left(\right.$ Dept $\left.h_{\text {water }}\right)$ \\
\hline DEFAULT & 1.623 & 0.967 & 0.604 & 0.538 \\
$\mathrm{~W} 1$ & 1.572 & 0.835 & 0.187 & 0.354 \\
$\mathrm{~W} 2$ & 1.542 & 0.752 & 0.150 & 0.289
\end{tabular}

TABLE XI: THE VALUES OF FITTING PARAMETERS AND THE COEFFICIENTS OF DETERMINATION (R2) VALUES FOR THE FOUR STUDIED INPUT PARAMETERS OF FATE MODEL IN JAP REGION

\begin{tabular}{lllll}
\hline \hline $\begin{array}{l}\text { Fitting } \\
\text { parameters }\end{array}$ & $r_{\mathrm{LSP}}$ & $\rho_{\mathrm{SNP}}$ & $\alpha_{2}$ & Depth $_{\text {water }}$ \\
\hline$A$ & $2.63 \cdot 10^{2}$ & 19.57 & 16.99 & 13.64 \\
$B$ & $-1.08 \cdot 10^{2}$ & -8.86 & -6.49 & -7.53 \\
$C$ & $2.98 \cdot 10^{-7}$ & $1.85 \cdot 10^{-6}$ & $1.10 \cdot 10^{-6}$ & $3.40 \cdot 10^{-7}$ \\
$D$ & $-1.52 \cdot 10^{2}$ & -10.22 & -10.37 & -5.92 \\
$E$ & $3.55 \cdot 10^{-10}$ & $3.36 \cdot 10^{-7}$ & $2.36 \cdot 10^{-7}$ & $1.57 \cdot 10^{-6}$ \\
$\mathrm{R}^{2}$ & 0.99885 & 0.99976 & 0.99976 & 0.99986 \\
\hline \hline
\end{tabular}

TABLE XII: THE VALUES OF FITTING PARAMETERS AND THE COEFFICIENTS OF DETERMINATION $\left(\mathrm{R}^{2}\right)$ VALUES FOR THE FOUR STUDIED INPUT PARAMETERS OF FATE MODEL IN DEFAULT REGION

\begin{tabular}{lllll}
\hline \hline $\begin{array}{l}\text { Fitting } \\
\text { parameters }\end{array}$ & $r_{\mathrm{LSP}}$ & $\rho_{\mathrm{SNP}}$ & $\alpha_{2}$ & Dept $_{\text {water }}$ \\
\hline$A$ & $4.67 \cdot 10^{2}$ & 4.88 & 26.10 & 3.41 \\
$B$ & $-3.35 \cdot 10^{2}$ & -1.66 & -14.70 & -1.21 \\
$C$ & $1.42 \cdot 10^{-35}$ & $1.01 \cdot 10^{-6}$ & $2.63 \cdot 10^{-7}$ & $1.06 \cdot 10^{-6}$ \\
$D$ & $-1.29 \cdot 10^{2}$ & -2.83 & -10.90 & -2.02 \\
$E$ & $2.47 \cdot 10^{-7}$ & $4.34 \cdot 10^{-6}$ & $1.52 \cdot 10^{-6}$ & $4.00 \cdot 10^{-6}$ \\
$\mathrm{R}^{2}$ & 0.99957 & 0.99999 & 0.99965 & 0.99999 \\
\hline \hline
\end{tabular}

TABLE XIII: THE VALUES OF FITTING PARAMETERS AND THE COEFFICIENTS OF DETERMINATION $\left(\mathrm{R}^{2}\right)$ VALUES FOR THE FOUR STUDIED INPUT PARAMETERS OF FATE MODEL IN W1 REGION 


\begin{tabular}{lllll}
$A$ & $5.53 \cdot 10^{2}$ & 15.20 & 13.70 & 10.30 \\
$B$ & $-4.16 \cdot 10^{2}$ & -7.29 & -5.48 & -4.84 \\
$C$ & $9.46 \cdot 10^{-95}$ & $2.16 \cdot 10^{-6}$ & $1.36 \cdot 10^{-6}$ & $1.90 \cdot 10^{-6}$ \\
$D$ & $-1.34 \cdot 10^{2}$ & -7.45 & -8.08 & -5.21 \\
$E$ & $2.96 \cdot 10^{-7}$ & $4.14 \cdot 10^{-7}$ & $2.96 \cdot 10^{-7}$ & $4.37 \cdot 10^{-7}$ \\
$\mathrm{R}^{2}$ & 0.99968 & 0.99982 & 0.99984 & 0.99989 \\
\hline \hline
\end{tabular}

TABLE XIV: The VALUeS of FitTing Parameters and the COEFFICIENTS OF DETERMINATION $\left(\mathrm{R}^{2}\right)$ VALUES FOR THE FOUR STUDIED INPUT PARAMETERS OF FATE MODEL IN W2 REGION

\begin{tabular}{lllll}
\hline \hline $\begin{array}{l}\text { Fitting } \\
\text { parameters }\end{array}$ & $r_{\mathrm{LSP}}$ & $\rho_{\mathrm{SNP}}$ & $\alpha_{2}$ & Depth $_{\text {water }}$ \\
\hline$A$ & $2.22 \cdot 10^{2}$ & 18.70 & 16.10 & 13.10 \\
$B$ & $-1.01 \cdot 10^{2}$ & -9.66 & -6.16 & -7.13 \\
$C$ & $3.09 \cdot 10^{-7}$ & $3.47 \cdot 10^{-7}$ & $1.15 \cdot 10^{-6}$ & $3.51 \cdot 10^{-7}$ \\
$D$ & $-1.18 \cdot 10^{2}$ & -8.57 & -9.84 & -5.73 \\
$E$ & $8.87 \cdot 10^{-10}$ & $1.89 \cdot 10^{-6}$ & $2.47 \cdot 10^{-7}$ & $1.60 \cdot 10^{-6}$ \\
$\mathrm{R}^{2}$ & 0.9985 & 0.99978 & 0.99977 & 0.99987 \\
\hline \hline
\end{tabular}

TABLE XV: The VALUeS of FitTing PaRAMETERS AND THE COEFFicients OF DETERMINATION $\left(R^{2}\right)$ VALUES FOR THE FOUR STUDIED INPUT PARAMETERS OF FATE MODEL IN W3 REGION

\begin{tabular}{lllll}
\multicolumn{5}{c}{ PARAMETERS OF FATE MODEL IN W3 REGION } \\
\hline \hline $\begin{array}{l}\text { Fitting } \\
\text { parameters }\end{array}$ & $r_{\text {LSP }}$ & $\rho_{\mathrm{SNP}}$ & $\alpha_{2}$ & Depth $h_{\text {water }}$ \\
\hline$A$ & 32.19 & 2.27 & 9.16 & 1.58 \\
$B$ & -12.71 & -0.48 & -4.60 & -0.35 \\
$C$ & $1.72 \cdot 10^{-6}$ & $1.68 \cdot 10^{-6}$ & $2.80 \cdot 10^{-6}$ & $1.78 \cdot 10^{-6}$ \\
$D$ & -18.23 & -1.48 & -4.19 & -1.08 \\
$E$ & $2.49 \cdot 10^{-7}$ & $6.62 \cdot 10^{-6}$ & $6.17 \cdot 10^{-7}$ & $6.32 \cdot 10^{-6}$ \\
$\mathrm{R}^{2}$ & 0.99944 & 1 & 0.99992 & 1 \\
\hline \hline
\end{tabular}

TABLE XVI: THe VALUeS OF FitTing PaRAMETERS AND the COEFFICIENTS OF DETERMINATION $\left(\mathrm{R}^{2}\right)$ VALUES FOR THE FOUR STUDIED INPUT PARAMETERS OF FATE MODEL IN W4 REGION

\begin{tabular}{lllll}
\hline \hline $\begin{array}{l}\text { Fitting } \\
\text { parameters }\end{array}$ & $r_{\mathrm{LSP}}$ & $\rho_{\mathrm{SNP}}$ & $\alpha_{2}$ & Depth $_{\text {water }}$ \\
\hline$A$ & $1.40 \cdot 10^{2}$ & 2.60 & 13.32 & 1.82 \\
$B$ & -56.51 & -1.68 & -6.39 & -1.22 \\
$C$ & $8.51 \cdot 10^{-24}$ & $6.12 \cdot 10^{-6}$ & $4.55 \cdot 10^{-7}$ & $5.85 \cdot 10^{-6}$ \\
$D$ & -80.38 & -0.60 & -6.49 & -0.43 \\
$E$ & $3.47 \cdot 10^{-7}$ & $1.53 \cdot 10^{-6}$ & $2.26 \cdot 10^{-6}$ & $1.63 \cdot 10^{-6}$ \\
$\mathrm{R}^{2}$ & 0.99713 & 1 & 0.99985 & 1 \\
\hline \hline
\end{tabular}

TABLE XVII: THE VALUES OF FITTING PARAMETERS AND THE COEFFICIENTS OF DETERMINATION $\left(\mathrm{R}^{2}\right)$ VALUES FOR THE FOUR STUDIED INPUT PARAMETERS OF FATE MODEL IN W5 REGION

\begin{tabular}{|c|c|c|c|c|}
\hline $\begin{array}{l}\text { Fitting } \\
\text { parameters }\end{array}$ & $r_{\mathrm{LSP}}$ & $\rho_{\mathrm{SNP}}$ & $\alpha_{2}$ & Depth $_{\text {water }}$ \\
\hline$A$ & $1.46 \cdot 10^{3}$ & 60.06 & 0 & 41.94 \\
\hline$B$ & $-7.28 \cdot 10^{2}$ & -22.66 & 0 & -15.36 \\
\hline C & $3.73 \cdot 10^{-8}$ & $7.77 \cdot 10^{-7}$ & 0 & $6.14 \cdot 10^{-7}$ \\
\hline$D$ & $-7.28 \cdot 10^{2}$ & -36.83 & 0 & -26.37 \\
\hline E & $3.73 \cdot 10^{-8}$ & $1.26 \cdot 10^{-7}$ & 0 & $1.25 \cdot 10^{-7}$ \\
\hline $\mathrm{R}^{2}$ & 0.99954 & 0.99965 & 0 & 0.99987 \\
\hline
\end{tabular}

TABLE XVIII: THE VALUES OF FITTING PARAMETERS AND THE COEFFICIENTS OF DETERMINATION $\left(\mathrm{R}^{2}\right)$ VALUES FOR THE FOUR STUDIED INPUT PARAMETERS OF FATE MODEL IN W6 REGION

\begin{tabular}{lllll}
\hline \hline $\begin{array}{l}\text { Fitting } \\
\text { parameters }\end{array}$ & $r_{\text {LSP }}$ & $\rho_{\text {SNP }}$ & $\alpha_{2}$ & Depth $_{\text {water }}$ \\
\hline$A$ & $2.3 \cdot 10^{3}$ & 58.21 & 0 & 40.67 \\
$B$ & $-1.15 \cdot 10^{3}$ & -35.44 & 0 & -25.24 \\
$C$ & $3.22 \cdot 10^{-8}$ & $1.29 \cdot 10^{-7}$ & 0 & $1.28 \cdot 10^{-7}$ \\
$D$ & $-1.15 \cdot 10^{3}$ & -22.19 & 0 & -15.22 \\
$E$ & $3.22 \cdot 10^{-8}$ & $7.96 \cdot 10^{-7}$ & 0 & $6.27 \cdot 10^{-7}$
\end{tabular}

\begin{tabular}{|c|c|c|c|c|}
\hline $\mathrm{R}^{2}$ & 0.99981 & 0.99962 & 0 & 0.99986 \\
\hline \multicolumn{5}{|c|}{$\begin{array}{l}\text { TABLE XIX: THE VALUES OF FITTING PARAMETERS AND THE } \\
\text { COEFFICIENTS OF DETERMINATION }\left(\mathrm{R}^{2}\right) \text { VALUES FOR THE FOUR STUDIED } \\
\text { INPUT PARAMETERS OF FATE MODEL IN W7 REGION }\end{array}$} \\
\hline $\begin{array}{l}\text { Fitting } \\
\text { parameters }\end{array}$ & $r_{\mathrm{LSP}}$ & $\rho_{\mathrm{SNP}}$ & $\alpha_{2}$ & $D e p t h_{\text {water }}$ \\
\hline$A$ & $1.74 \cdot 10^{2}$ & 8.58 & 14.20 & 5.99 \\
\hline$B$ & -90.34 & -4.37 & -6.31 & -2.79 \\
\hline C & $3.26 \cdot 10^{-7}$ & $3.18 \cdot 10^{-6}$ & $1.63 \cdot 10^{-6}$ & $7.07 \cdot 10^{-7}$ \\
\hline$D$ & -81.43 & -3.77 & -7.67 & -3.01 \\
\hline$E$ & $9.55 \cdot 10^{-10}$ & $6.85 \cdot 10^{-7}$ & $3.49 \cdot 10^{-7}$ & $2.82 \cdot 10^{-6}$ \\
\hline $\mathrm{R}^{2}$ & 0.99786 & 0.99994 & 0.99985 & 0.99996 \\
\hline
\end{tabular}

TABLE XX: THE VALUeS OF FitTing PARAMETERS AND THE COEFFiCIENTS OF DETERMINATION $\left(\mathrm{R}^{2}\right)$ VALUES FOR THE FOUR STUDIED INPUT PARAMETERS OF FATE MODEL IN W8 REGION

\begin{tabular}{lllll}
\hline \hline $\begin{array}{l}\text { Fitting } \\
\text { parameters }\end{array}$ & $r_{\mathrm{LSP}}$ & $\rho_{\mathrm{SNP}}$ & $\alpha_{2}$ & Depth $_{\text {water }}$ \\
\hline$A$ & 32.88 & 5.54 & 7.63 & 3.84 \\
$B$ & -12.92 & -2.05 & -3.75 & -2.14 \\
$C$ & $1.70 \cdot 10^{-6}$ & $9.20 \cdot 10^{-7}$ & $5.53 \cdot 10^{-7}$ & $3.56 \cdot 10^{-6}$ \\
$D$ & -18.72 & -3.12 & -3.69 & -1.53 \\
$E$ & $2.45 \cdot 10^{-7}$ & $3.99 \cdot 10^{-6}$ & $2.27 \cdot 10^{-6}$ & $9.45 \cdot 10^{-7}$ \\
$\mathrm{R}^{2}$ & 0.99942 & 0.99999 & 0.99992 & 0.99999 \\
\hline \hline
\end{tabular}

TABLE XXI: THE VALUES OF FITTING PARAMETERS AND THE COEFFICIENTS OF DETERMINATION $\left(\mathrm{R}^{2}\right)$ VALUES FOR THE FOUR STUDIED INPUT PARAMETERS OF FATE MODEL IN W9 REGION

\begin{tabular}{lllll}
\hline \hline $\begin{array}{l}\text { Fitting } \\
\text { parameters }\end{array}$ & $r_{\mathrm{LSP}}$ & $\rho_{\mathrm{SNP}}$ & $\alpha_{2}$ & Dept $_{\text {water }}$ \\
\hline$A$ & $3.13 \cdot 10^{2}$ & 28.67 & 12.10 & 19.99 \\
$B$ & $-1.15 \cdot 10^{2}$ & -11.79 & -7.41 & -7.84 \\
$C$ & $2.89 \cdot 10^{-7}$ & $1.46 \cdot 10^{-6}$ & $2.10 \cdot 10^{-7}$ & $1.19 \cdot 10^{-6}$ \\
$D$ & $-1.96 \cdot 10^{2}$ & -16.40 & -4.60 & -11.96 \\
$E$ & $4.65 \cdot 10^{-10}$ & $2.45 \cdot 10^{-7}$ & $9.28 \cdot 10^{-7}$ & $2.44 \cdot 10^{-7}$ \\
$\mathrm{R}^{2}$ & 0.99914 & 0.99959 & 0.99977 & 0.99974 \\
\hline \hline
\end{tabular}

TABLE XXII: THE VALUES OF FITTING PARAMETERS AND THE COEFFICIENTS OF DETERMINATION $\left(\mathrm{R}^{2}\right)$ VALUES FOR THE FOUR STUDIED INPUT PARAMETERS OF FATE MODEL IN W10 REGION

\begin{tabular}{lllll}
\hline \hline $\begin{array}{l}\text { Fitting } \\
\text { parameters }\end{array}$ & $r_{\mathrm{LSP}}$ & $\rho_{\mathrm{SNP}}$ & $\alpha_{2}$ & Depth $_{\text {water }}$ \\
\hline$A$ & $7.52 \cdot 10^{2}$ & 28.56 & 12.22 & 19.96 \\
$B$ & $-1.42 \cdot 10^{2}$ & -11.77 & -4.61 & -11.89 \\
$C$ & $2.62 \cdot 10^{-7}$ & $1.48 \cdot 10^{-6}$ & $9.65 \cdot 10^{-7}$ & $2.50 \cdot 10^{-7}$ \\
$D$ & $-6.07 \cdot 10^{2}$ & -16.30 & -7.53 & -7.87 \\
$E$ & $2.36 \cdot 10^{-9}$ & $2.48 \cdot 10^{-7}$ & $2.16 \cdot 10^{-7}$ & $1.22 \cdot 10^{-6}$ \\
$\mathrm{R}^{2}$ & 0.99982 & 0.99959 & 0.99977 & 0.99974 \\
\hline \hline
\end{tabular}

TABLE XXIII: THE VALUES OF FITTING PARAMETERS AND THE COEFFICIENTS OF DETERMINATION $\left(\mathrm{R}^{2}\right)$ VALUES FOR THE FOUR STUDIED INPUT PARAMETERS OF FATE MODEL IN W12 REGION

\begin{tabular}{lllll}
\hline \hline $\begin{array}{l}\text { Fitting } \\
\text { parameters }\end{array}$ & $r_{\mathrm{LSP}}$ & $\rho_{\mathrm{SNP}}$ & $\alpha_{2}$ & Depth $_{\text {water }}$ \\
\hline$A$ & $1.06 \cdot 10^{3}$ & 23.45 & 14.47 & 15.09 \\
$B$ & $-9.11 \cdot 10^{2}$ & -12.81 & -5.44 & -8.59 \\
$C$ & $4.16 \cdot 10^{-32}$ & $2.92 \cdot 10^{-7}$ & $1.07 \cdot 10^{-6}$ & $3.11 \cdot 10^{-7}$ \\
$D$ & $-1.49 \cdot 10^{2}$ & -10.15 & -8.92 & -6.31 \\
$E$ & $2.56 \cdot 10^{-7}$ & $1.68 \cdot 10^{-6}$ & $2.34 \cdot 10^{-7}$ & $1.46 \cdot 10^{-6}$ \\
$\mathrm{R}^{2}$ & 0.99991 & 0.9997 & 0.99977 & 0.99983 \\
\hline \hline
\end{tabular}

TABLE XXIV: THE VALUES OF FITTING PARAMETERS AND THE COEFFICIENTS OF DETERMINATION $\left(\mathrm{R}^{2}\right)$ VALUES FOR THE FOUR STUDIED INPUT PARAMETERS OF FATE MODEL IN W13 REGION 


\begin{tabular}{lllll}
\hline \hline $\begin{array}{l}\text { Fitting } \\
\text { parameters }\end{array}$ & $r_{\mathrm{LSP}}$ & $\rho_{\mathrm{SNP}}$ & $\alpha_{2}$ & Depth $_{\text {water }}$ \\
\hline$A$ & $6.40 \cdot 10^{2}$ & 17.22 & 11.90 & 12.04 \\
$B$ & $-1.38 \cdot 10^{2}$ & -8.67 & -7.10 & -6.36 \\
$C$ & $2.65 \cdot 10^{-7}$ & $3.74 \cdot 10^{-7}$ & $2.98 \cdot 10^{-7}$ & $3.82 \cdot 10^{-7}$ \\
$D$ & $-4.99 \cdot 10^{2}$ & -8.05 & -4.69 & -5.47 \\
$E$ & $8.35 \cdot 10^{-11}$ & $2.01 \cdot 10^{-6}$ & $1.34 \cdot 10^{-6}$ & $1.72 \cdot 10^{-6}$ \\
$\mathrm{R}^{2}$ & 0.99976 & 0.99979 & 0.99985 & 0.99988 \\
\hline \hline
\end{tabular}

TABLE XXV: THE VALUES OF FitTING PARAMETERS AND THE COEFFICIENTS OF DETERMINATION $\left(\mathrm{R}^{2}\right)$ VALUES FOR THE FOUR STUDIED INPUT PARAMETERS OF FATE MODEL IN W14 REGION

\begin{tabular}{lllll}
\hline \hline $\begin{array}{l}\text { Fitting } \\
\text { parameters }\end{array}$ & $r_{\mathrm{LSP}}$ & $\rho_{\mathrm{SNP}}$ & $\alpha_{2}$ & Depth $_{\text {water }}$ \\
\hline$A$ & 85.26 & 4.25 & 18.74 & 2.96 \\
$B$ & -56.97 & -2.53 & -8.48 & -0.98 \\
$C$ & $1.13 \cdot 10^{-7}$ & $4.65 \cdot 10^{-6}$ & $1.78 \cdot 10^{-6}$ & $1.16 \cdot 10^{-6}$ \\
$D$ & -26.49 & -1.33 & -9.85 & -1.81 \\
$E$ & $9.20 \cdot 10^{-7}$ & $1.10 \cdot 10^{-6}$ & $3.35 \cdot 10^{-7}$ & $4.30 \cdot 10^{-6}$ \\
$\mathrm{R}^{2}$ & 0.99936 & 0.99999 & 0.99979 & 1 \\
\hline \hline
\end{tabular}

TABLE XXVI: THE VALUES OF FITTING PARAMETERS AND THE COEFFICIENTS OF DETERMINATION $\left(\mathrm{R}^{2}\right)$ VALUES FOR THE FOUR STUDIED INPUT PARAMETERS OF FATE MODEL IN IND REGION

\begin{tabular}{lllll}
\hline \hline $\begin{array}{l}\text { Fitting } \\
\text { parameters }\end{array}$ & $r_{\mathrm{LSP}}$ & $\rho_{\mathrm{SNP}}$ & $\alpha_{2}$ & Depth $_{\text {water }}$ \\
\hline$A$ & $4.56 \cdot 10^{2}$ & 19.51 & 17.35 & 13.63 \\
$B$ & $-1.28 \cdot 10^{2}$ & -10.16 & -6.64 & -7.48 \\
$C$ & $2.75 \cdot 10^{-7}$ & $3.37 \cdot 10^{-7}$ & $1.11 \cdot 10^{-6}$ & $3.44 \cdot 10^{-7}$ \\
$D$ & $-3.25 \cdot 10^{2}$ & -8.85 & -10.56 & -5.95 \\
$E$ & $5.75 \cdot 10^{-11}$ & $1.86 \cdot 10^{-6}$ & $2.36 \cdot 10^{-7}$ & $1.58 \cdot 10^{-6}$ \\
$\mathrm{R}^{2}$ & 0.99955 & 0.99976 & 0.99975 & 0.99986 \\
\hline \hline
\end{tabular}

TABLE XXVII: THE VALUES OF FITTING PARAMETERS AND THE COEFFICIENTS OF DETERMINATION $\left(\mathrm{R}^{2}\right)$ VALUES FOR THE FOUR STUDIED INPUT PARAMETERS OF FATE MODEL IN CHI REGION

\begin{tabular}{lllll}
\hline \hline $\begin{array}{l}\text { Fitting } \\
\text { parameters }\end{array}$ & $r_{\text {LSP }}$ & $\rho_{\mathrm{SNP}}$ & $\alpha_{2}$ & Depth $h_{\text {water }}$ \\
\hline$A$ & $4.82 \cdot 10^{2}$ & 19.62 & 17.47 & 13.70 \\
$B$ & $-1.30 \cdot 10^{2}$ & -8.89 & -6.69 & -7.53 \\
$C$ & $2.73 \cdot 10^{-7}$ & $1.86 \cdot 10^{-6}$ & $1.10 \cdot 10^{-6}$ & $3.42 \cdot 10^{-7}$ \\
$D$ & $-3.49 \cdot 10^{2}$ & -10.23 & -10.63 & -5.98 \\
$E$ & $2.79 \cdot 10^{-11}$ & $3.36 \cdot 10^{-7}$ & $2.35 \cdot 10^{-7}$ & $1.58 \cdot 10^{-6}$ \\
$\mathrm{R}^{2}$ & 0.99959 & 0.99976 & 0.99975 & 0.99986 \\
\hline \hline
\end{tabular}

\section{ACKNOWLEDGMENT}

Yubing Pu kindly thanks the China Scholarship Council (CSC) for funding his Ph.D. fellowship in France.

\section{REFERENCES}

[1] K. Juganson, A. Ivask, I. Blinova, M. Mortimer, and A. Kahru, "NanoE-Tox: New and in-depth database concerning ecotoxicity of nanomaterials," Beilstein J Nanotechnol, vol. 6, pp. 1788-1804, 2015.

[2] S. J. Tesh and T. B. Scott, "Nano-composites for water remediation: A review," Advanced Materials, vol. 26, pp. 6056-6068, 2014

[3] T. Y. Sun, N. A. Bornhoft, K. Hungerbuhler, and B. Nowack, "Dynamic probabilistic modeling of environmental emissions of engineered nanomaterials," Environmental Science \& Technology, vol. 50, pp. 4701-4711, 2016

[4] F. Gottschalk and B. Nowack, "The release of engineered nanomaterials to the environment," Journal of Environmental Monitoring, vol. 13, pp. 1145-1155, 2011.

[5] J. R. Conway, A. S. Adeleye, J. Gardea-Torresdey, and A. A. Keller, "Aggregation, dissolution, and transformation of copper nanoparticles in natural waters," Environmental Science \& Technology, vol. 49, pp. 2749-2756, 2015.
[6] J. T. Quik, "Fate of nanoparticles in the aquatic environment," Ph.D dissertation, Radboud University Nijmegen, Netherlands, 2013.

[7] A. A. Noyes and W. R. Whitney, "The rate of solution of solid substances in their own solutions," Journal of the American Chemical Society, vol. 19, pp. 930-934, 1897

[8] J. A. Meesters, A. A. Koelmans, J. T. Quik, A. J. Hendriks, and D. van de Meent, "Multimedia modeling of engineered nanoparticles with SimpleBox4nano: model definition and evaluation," Environmental Science \& Technology, vol. 48, pp. 5726-5736, 2014.

[9] B. Salieri, S. Righi, A. Pasteris, and S. I. Olsen, "Freshwater ecotoxicity characterisation factor for metal oxide nanoparticles: A case study on titanium dioxide nanoparticle," Science of the Total Environment, vol. 505, pp. 494-502, 2015.

[10] J. Schmidt and W. Vogelsberger, "Dissolution kinetics of titanium dioxide nanoparticles: the observation of an unusual kinetic size effect," Journal of Physical Chemistry B, vol. 110, pp. 3955-3963, 2006.

[11] R. B. Reed, D. A. Ladner, C. P. Higgins, P. Westerhoff, and J. F. Ranville, "Solubility of nano-zinc oxide in environmentally and biologically important matrices," Environmental Toxicology and Chemistry, vol. 31, pp. 93-99, 2012.

[12] Y. Pu, F. Tang, P. M. Adam, B. Laratte, and R. E. Ionescu, "Fate and characterization factors of nanoparticles in seventeen subcontinental freshwaters: A case study on copper nanoparticles," Environmental Science \& Technology, vol. 50, pp. 9370-9379, 2016.

[13] J. Liu and R. H. Hurt, "Ion release kinetics and particle persistence in aqueous nano-silver colloids," Environmental Science \& Technology, vol. 44, pp. 2169-2175, 2010.

[14] J. T. Quik, J. A. Vonk, S. F. Hansen, A. Baun, and D. Meent, "How to assess exposure of aquatic organisms to manufactured nanoparticles?" Environment International, vol. 37, pp. 1068-1077, 2011.

[15] S. Shaked, "Multi-continental multimedia model of pollutant intake and application to impacts of global emissions and globally traded goods," Ph.D. dissertation, University of Michigan, Ann Arbor, MI, 2011.

[16] A. Praetorius, M. Scheringer, and K. Hungerbuhler, "Development of environmental fate models for engineered nanoparticles - A case study of $\mathrm{TiO}_{2}$ nanoparticles in the Rhine River," Environmental Science \& Technology, vol. 46, pp. 6705-6713, 2012.

[17] B. Lartiges, S. Deneux-Mustin, G. Villemin, C. Mustin, O. Barres, M. Chamerois, B. Gerard, and M. Babut, "Composition, structure and size distribution of suspended particulates from the Rhine River," Water Research, vol. 35, pp. 808-816, 2001

[18] P. Fantke, X. Bengoa, B. Chappert, Y. Dong, C. Guignard, M. Z. Hauschild, M. Huijbregts, O. Jolliet, A. Kounina, and V. Magaud USEtox ${ }^{\circledR} 2.0$ Documentation (Version 1.00), USEtox ${ }^{\circledR}$ Team, 2015

[19] MathWorks - MATLAB and simulink for technical computing website. [Online]. Available: http://www.mathworks.com/index.html

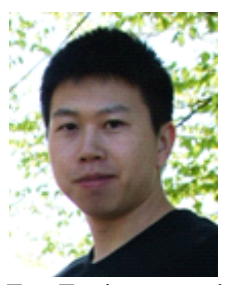

Yubing Pu is currently pursuing his Ph.D. studies at University of Technology of Troyes under the supervision of Prof. Ionescu and Laratte. He received his bachelor degree in environmental science in 2010 at Shandong Jianzhu University and master degree in chemistry in 2013 at China University of Geosciences (Beijing). In 2011 and 2012, he engaged in scientific research as a visiting student in Research Center for Eco-Environmental Sciences, Chinese Academy of Sciences in Beijing.

His current research work is mainly focusing on the nanosafety issues related to the impacts of manufactured nanomaterials on human and ecosystems and the behavior of nanomaterials in the environment.

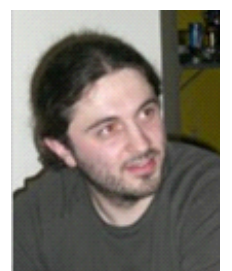

Bertrand Laratte is an associate professor at the Institute of Mechanics and Engineering, Arts et Métiers ParisTech. Between 2014 and 2016, he was an associate professor at the Research Centre for Environmental Studies and Sustainability, University of Technology of Troyes (UTT). He received his Eng. degree in industrial system in 2004 at UTT, M.Sc degree in environmental management and sustainable development in 2005 at UTT, and Ph.D. degree in 2013 at UTT. He spent more than 5 years as an expert in life cycle assessment in a consulting company before to join UTT for his Ph.D. He works with multidisciplinary researchers like biologist, physicist, etc. to update life cycle impact assessment methodologies.

His research interests mainly merge experimentation and collection data with environmental modeling to assess the potential environmental impacts. 
His contribution has the ambition to help mechanical design and industrial processes in order to reduce the environment risks.

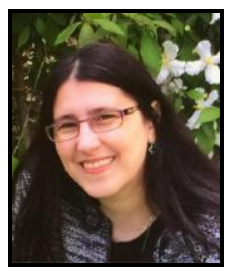

Rodica Elena Ionescu is an associate professor at the University of Technology of Troyes, France, in the Nanotechnology and Optical Instrumentation Laboratory since December $4^{\text {th }} 2009$. She earned one Ph.D. from the Ben-Gurion University of Negev, Israel in Biotechnological Engineering in 2004 and a second $\mathrm{Ph} . \mathrm{D}$. in Chemistry, from the University of Bucharest, in 2007.

She has performed several post-doctoral positions in France in the field of electrochemical biosensors. Between February-October 2008, Dr. Ionescu was a researcher fellow at the National Nanotechnology Laboratory, Lecce (Italy) working on impedimetric cell-chips based interdigitated microlectrodes. Thanks to the obtained research grants, Dr. Ionescu developed novel acoustic and optical platforms for ultrasensitive detection of biomolecules and pesticides. In 2012, Dr. Ionescu was awarded with a national OSEO Innovation grant. Between April $1^{\text {st }} 2014$ to March 30, 2015

Dr. Ionescu was the scientific research manager of a Proof-of Concept (POC) Grant-NRF-POC 002-026 supported by the Singapore National Research Foundation concerning the Electrochemical lateral flow biosensor detection and quantification of Dengue virus in whole blood at the Nanyang Technological University, School of Materials Science and Engineering under an international CREATE-NTU-HUJ-BGU program.

Her current research activities include the development of multi-analyte biosensors, specific (bio)functionalization of surfaces, atomic force microscopy nanopipette applications, controllable synthesis of nanoparticle, evaluation of toxicity of nanoparticles and water pollutants to living cells and microorganisms. 